\title{
Article \\ An Atomistic Investigation of Adsorption of Bone Morphogenetic Protein-2 on Gold with Nanoscale Topographies
}

\author{
Izabele Marquetti ${ }^{1}$ and Salil Desai ${ }^{2, *} \mathbb{C}$
}

1 Department of Biomedical Affairs, Edward Via College of Osteopathic Medicine, Spartanburg, SC 29303, USA; ibmarquetti@gmail.com

2 Center for Excellence in Product Design and Advanced Manufacturing, North Carolina A \& T State University, Greensboro, NC 27411, USA

* Correspondence: sdesai@ncat.edu

Citation: Marquetti, I.; Desai, S. An Atomistic Investigation of Adsorption of Bone Morphogenetic Protein-2 on Gold with Nanoscale

Topographies. Surfaces 2022, 5,

176-185. https://doi.org/10.3390/ surfaces5010010

Academic Editor: Gaetano Granozzi

Received: 10 November 2021

Accepted: 9 February 2022

Published: 15 February 2022

Publisher's Note: MDPI stays neutral with regard to jurisdictional claims in published maps and institutional affiliations.

Copyright: (c) 2022 by the authors. Licensee MDPI, Basel, Switzerland. This article is an open access article distributed under the terms and conditions of the Creative Commons Attribution (CC BY) license (https:// creativecommons.org/licenses/by/ $4.0 /)$.

\begin{abstract}
Nanoscale surface topographies mediated with biochemical cues influence the differentiation of stem cells into different lineages. This research focuses on the adsorption behavior of bone morphogenetic protein (BMP-2) on nanopatterned gold substrates, which can aid in the differentiation of bone and cartilage tissue constructs. The gold substrates were patterned as flat, pillar, linear grating, and linear-grating deep based, and the BMP-2 conformation in end-on configuration was studied over $20 \mathrm{~ns}$. The linear grating deep substrate pattern had the highest adsorption energy of around $125 \mathrm{~kJ} / \mathrm{mol}$ and maintained its radius of gyration of $18.5 \AA$, indicating a stable adsorption behavior. Secondary structures including $\alpha$-helix and $\beta$-sheet displayed no denaturation, and thus, the bioavailability of the BMP-2, for the deep linear-grating pattern. Ramachandran plots for the wrist and knuckle epitopes indicated no steric hindrances and provided binding sites to type I and type II receptors. The deep linear-grating substrate had the highest number of contacts ( 88 atoms) within $5 \AA$ of the gold substrate, indicating its preferred nanoscale pattern choice among the substrates considered. This research provides new insights into the atomistic adsorption of BMP-2 on nanoscale topographies of a gold substrate, with applications in biomedical implants and regenerative medicine.
\end{abstract}

Keywords: adsorption; bone morphogenetic protein-2; gold; molecular dynamics; nanoscale topographies; regenerative medicine; tissue engineering

\section{Introduction}

Protein adsorption on a biomaterial for tissue engineering applications relies on the conformational and orientation behavior of the protein to obtain biological responses, including biocompatibility and cellular interactions [1,2]. It influences the sensitivity and efficiency of protein-cell interactions [3]. Protein and surface properties and environmental conditions strongly guide adsorption [3]. Protein properties include size, rigidity, and residue charges; surface properties include wettability, charge, and topology; environmental conditions include temperature, $\mathrm{pH}$, hydrophobicity, and ionic strength [1]. An adequate topology and morphology of a biomaterial surface can promote cell adhesion, proliferation, and migration [4,5]. Controlled orientation of adsorption assures better biological functions for the specific application [1]. Therefore, surface modification can improve the functionality and biocompatibility according to the desired biological application [6].

Among the proteins used for bone tissue engineering purposes, bone morphogenetic protein-2 (BMP-2) is responsible for the formation and restoration of bone structure because it differentiates and proliferates osteoblasts [7-9]. Human recombinant BMP-2 (rhBMP-2) is approved by the US Food and Drug Administration (FDA) for clinical use in lumbar fusion [10], acute open tibial shaft fractures [11], and as an alternative to autogenous bone grafting for sinus augmentation and alveolar ridge augmentation [12]. However, the effective healing of bone in humans requires high concentrations of proteins, which increases its 
clinical side effects, including postoperative inflammation and infection, tissue swelling, ectopic bone formation, and improper adipogenesis [9]. An excessive dosage of BMP-2 is related to most of the adverse reactions while not always promoting increased fusion rates in the spine and long bone nonunion treatments [13]. Additionally, it still presents some challenges related to its delivery process, including uncontrolled release [14-17].

BMP-2 requires a biomaterial that will maintain protein concentration during tissue regeneration, allowing prolonged release to induce bone repair effectively [18]. The biomaterial's specific topographic patterns can enhance protein-surface interactions facilitating protein adsorption [19]. The behavior of adsorption on the surface of biomaterials has been studied by both experimental and computational methods. Experimental studies of protein adsorption include approaches such as atomic force microscopy, secondary ion mass spectroscopy, and sum-frequency generation spectroscopy, which allow indirect predictions of orientation and conformational changes [20]. However, it is insufficient to quantify the orientation and conformation at the molecular level [1]. Molecular dynamics (MD) simulations facilitate the understanding of biological processes, allowing an in-deep investigation of protein adsorption on biomaterials.

In this research, the BMP-2 monomer is implemented as a precursor, to evaluate its structural integrity in light of its eventual usage in both homodimeric and heterodimeric ligand formats [21-24]. Several researchers have investigated the adsorption behavior and structural conformity of BMP-2 monomers on different substrates, to provide benchmarks on their performance as dimers [25-29]. Our team extends similar approaches in modeling BMP-2 monomers for both configuration orientations and substrate compatibility before proceeding with dimer BMP-2 molecules. Furthermore, studying the BMP-2 monomer can aid in upscaling protein expression and purification strategies, to produce higher yields of biologically active BMP2 dimer. This can be attained by increasing the adsorption of the BMP-2 monomers on gold topographies, which could assist with ligand dimerization during protein refolding.

Our prior research has evaluated the adsorption behavior of four orthogonal orientations of BMP-2 protein with hydrophilic silicon dioxide substrate [30]. The end-on configurations had favorable adsorption characteristics, along with a robust secondary structure. These four orientations were further studied with hydrophobic (gold) and hydrophilic (silicon nitride) flat substrates [31]. Denaturation of secondary structure was observed with silicon nitride due to destruction of the BMP-2 protein, whereas higher bioavailability of BMP-2 was observed with the gold substrate. It was revealed that BMP-2 adsorption relies on the three-way interaction between the protein, the dissolution media, and the substrate. The end-on configuration was deemed as the most suitable configuration for the gold substrate. Our group carried out similar investigations with graphite substrate, which has higher biocompatibility, low friction coefficient, and bone equivalent stiffness and is, thus, used as an implant material [32].

Currently, a few studies have analyzed the effects of patterned materials on the BMP-2 adsorption behavior using MD simulations. Huang Y. (2015) found that surface roughness affects the BMP-2 biding on hydroxyapatite (HAP), while polished crystal surface (thickness $33.1 \pm 5.6 \mathrm{~nm}$ ) enhances protein-surface interaction. Huang L. (2018) [33] studied the adsorption-desorption of BMP-2 on nanopatterned HAP structures, achieving less protein conformational changes and higher cysteine-knot stability with patterned HAP 1:1 (ridge:groove ratio), compared with a flat surface.

In this study, MD simulations were used to understand the effect of patterned gold on the BMP-2 adsorption behavior. Gold nanostructures have been used for different applications in the medical field, such as biosensors, drug delivery, bioimaging, and biocatalysis [34]. However, to our knowledge, there are no MD studies on the effects of topographic patterns of this material on the conformational changes of BMP-2. 


\section{Materials and Methods}

The BMP-2 crystallographic structure Figure 1 (ID:3BMP) was retrieved from the RCSB Protein Data Bank [35], https: / / www.rcsb.org/ (accessed on 19 January 2022). This structure contains a four-turn $\alpha$-helix and two antiparallel double-stranded $\beta$-sheets. The residues glutamic acid (Glu) and aspartic acid (Asp) were deprotonated, and lysine (Lys) and arginine (Arg) were protonated. Additionally, the histidine (His) residue was considered in the protonated state.

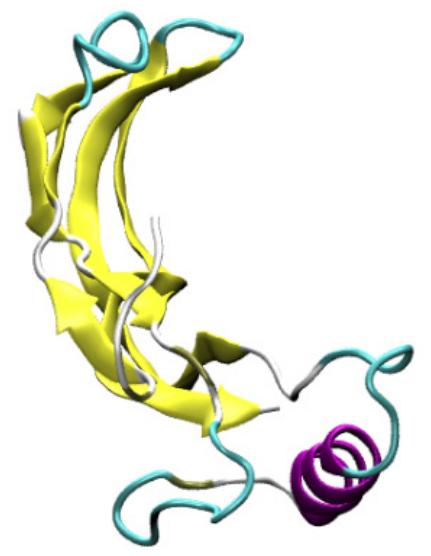

Figure 1. Initial BMP-2 configuration.

MD simulations were performed using NAMD source code version 2.11 (Phillips, 2005) with CHARMM force field on a 64-bit Linux Fedora platform. K20 and K40 (2496 and 2880 cores) graphical processing units (GPUs) from NVIDIA ${ }^{\circledR}$ Corporation were used for acceleration, in conjunction with K80 (2992 cores) GPU computing resources from XSEDE [36].

Visual Molecular Dynamics (VMD) was used to create the models. The BMP-2 monomer was solvated in a sphere of water with an explicit TIP3P model, and ions of NA ${ }^{+}$ and $\mathrm{Cl}^{-}$were added at a concentration of $0.15 \mathrm{~mol} / \mathrm{L}$. The solvated system had a total charge of $2.28 \times 10^{-6}$ (i.e., neutral) and a $6.5 \mathrm{~nm}$ droplet with 13,863 atoms. The bonded and nonbonded parameters for the protein, water, and salt ions were obtained from the CHARMM force fields [37]. The protein was placed in an end-on orientation on the top center of four gold substrates: flat (FLT), pillars (FLT), shallow linear grating (SLG), and deep linear grating (DLG). This specific orientation improves BMP-2 adsorption on silicon dioxide, silicon nitride, and gold [30-32].

The gold substrates were built using the Inorganic Builder plugin on VMD (unit cell parameters $\mathrm{a}=\mathrm{b}=\mathrm{c}=4.08 \AA$ ), with a lattice plane (001). The patterns were built by excluding areas of a flat substrate (Figure 2). The nonbonded force field parameters for gold were $\sigma_{\mathrm{ij}}=3.694 \AA$ and $\varepsilon_{\mathrm{ij}}=-0.039 \mathrm{kcal} / \mathrm{mol}$ [38]. Periodic boundary condition was considered in $\mathrm{x}$ and $\mathrm{y}$ directions. The simulations were performed at a constant temperature of $310 \mathrm{~K}$, using Langevin temperature control. All atoms in the gold substrate were fixed. All results were analyzed with VMD and MATLAB R2017a software.

The simulations were performed for $20 \mathrm{~ns}$, with a $0.2 \mathrm{~ns}$ minimization step and $2 \mathrm{fs}$ integration step. The cutoff distance for Van der Waals interactions was set to $12 \AA$.

Adsorption energy and the number of residues to interact with the surface were used as parameters to evaluate the BMP-2 adsorption on the substrate, which includes non-bonded and electrostatic energy. The Van der Waals energy, nonbonded, is an attractiverepulsive weak force because of noncovalent bonds; and electrostatic energy from different charge distributions.

$$
\mathrm{U}_{\mathrm{VdW}}=\sum_{\mathrm{i}} \sum_{\mathrm{j}>1} 4 \varepsilon_{\mathrm{ij}}\left[\left(\frac{\sigma_{\mathrm{ij}}}{\mathrm{r}_{\mathrm{ij}}}\right)^{12}-\left(\frac{\sigma_{\mathrm{ij}}}{\mathrm{r}_{\mathrm{ij}}}\right)^{6}\right]
$$




$$
\mathrm{U}_{\text {Coulomb }}=\sum_{\mathrm{i}} \sum_{\mathrm{j}>1} \frac{\mathrm{q}_{\mathrm{i}} \mathrm{q}_{\mathrm{j}}}{4 \pi \varepsilon_{0} \mathrm{r}_{\mathrm{ij}}}
$$

where $r_{i j}$ is the distance between atoms $i$ and $j, \varepsilon_{i j}$ is the depth of the potential well, $q$ is the electric charge, and $\sigma_{i j}$ is the distance when the potential is zero.

The number of residue contacts is the number of atoms in one residue of the protein that are within $5 \AA$ to the surface of the substrate [39].

a
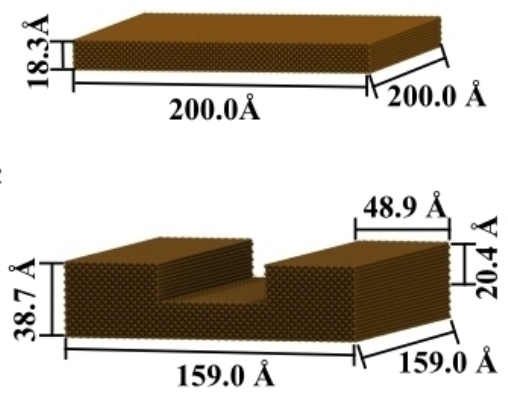

b

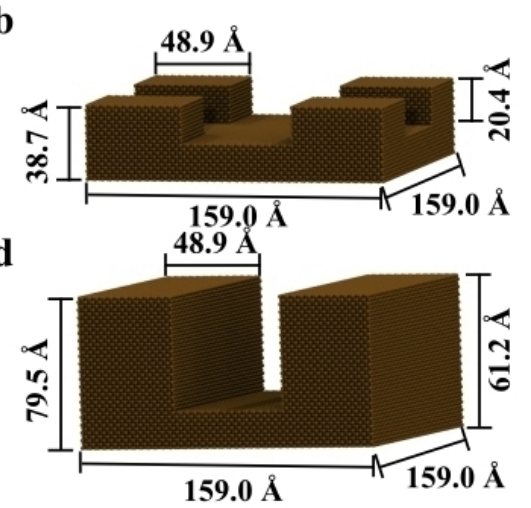

Figure 2. Different nanoscale topographies: (a) flat (FLT); (b) pillars (PLR); (c) shallow linear grating (SLG); (d) deep linear grating (DLG).

The equilibration of the system was evaluated by the root-mean-square deviation (RMSD), which indicates the position of the atoms during the MD simulations [40].

$$
\operatorname{RMSD}=\sqrt{\frac{\sum_{\mathrm{i}=1}^{\mathrm{N}_{\alpha}}\left(\mathrm{r}_{\mathrm{i}}\left(\mathrm{t}_{1}\right)-\mathrm{r}_{\mathrm{i}}\left(\mathrm{t}_{2}\right)\right)^{2}}{\mathrm{~N}_{\alpha}}}
$$

where $N_{\alpha}$ is the number of atoms in which position are being compared, and $r_{i}(t)$ is the position of atom $i$ at time $(t)$.

Substantial movement of folding or unfolding of the protein induces denaturation and, consequently, loss of protein bioactivity. The radius of gyration $\left(R_{g}\right)$ indicates the protein conformation during the simulations, i.e., the level of folding.

$$
\mathrm{R}_{\mathrm{g}}=\sqrt{\frac{\sum_{\mathrm{i}}\left|\mathrm{r}_{\mathrm{i}}-\mathrm{r}_{\mathrm{com}}\right|^{2} \mathrm{~m}_{\mathrm{i}}}{\sum_{\mathrm{i}} \mathrm{m}_{\mathrm{i}}}}
$$

where $\left|r_{i}-r_{\text {com }}\right|$ is the distance of the atom $i$ with mass $m_{i}$ to the center of mass.

Protein bioactivity was evaluated based on the initial and final secondary structure. The loss of secondary structure, as well as broken $\alpha$-helix and $\beta$-sheet structures, indicates that significant denaturation occurred.

\section{Results and Discussion}

The effects of nanoscale topographical patterns on the protein adsorption behavior were evaluated over time. Figure 3 shows the final BMP-2 conformation after 20 ns for the different patterned substrates. The protein adsorbed with an $\alpha$-helix structure parallel to the surface on the flat and linear-grating substrates. All patterned substrates had residues from $\alpha$-helix and $\beta$-sheet structures adsorbing in a perpendicular position, caused by the influence of the rearrangement of salt ions. 


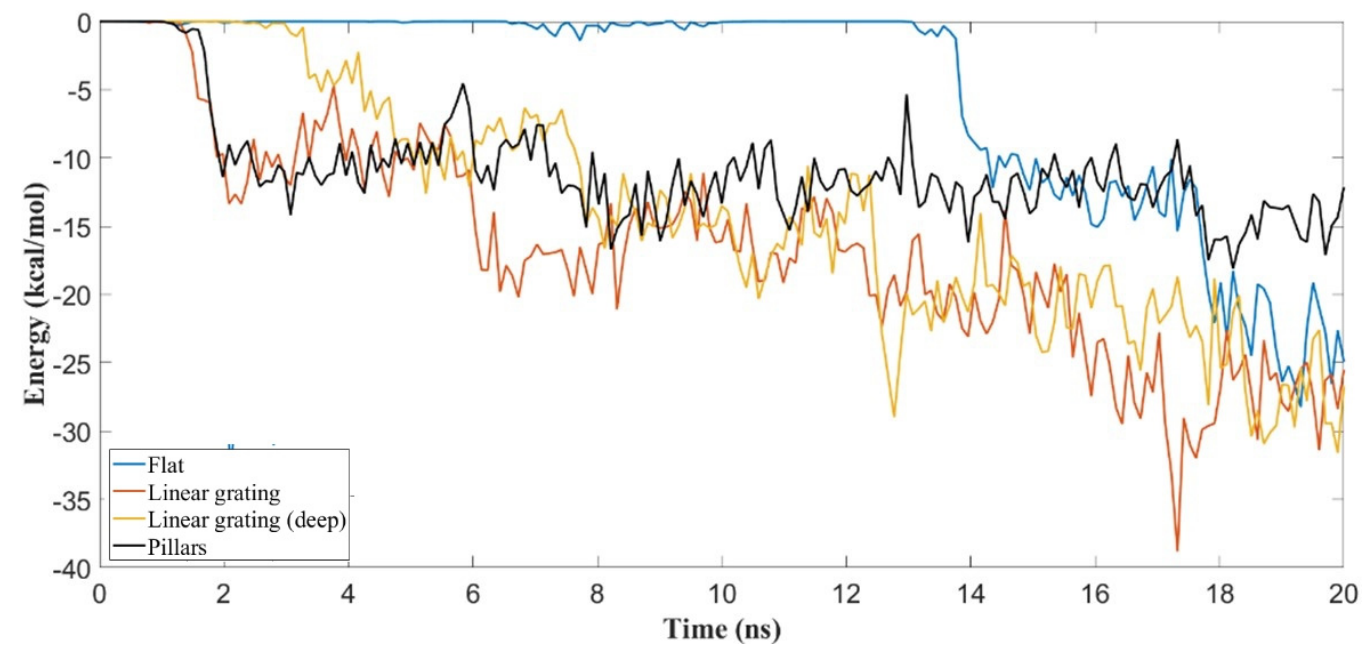

Figure 3. Van der Waals (VdW) and electrostatic (el) energies for different nanoscale topographies.

A previous study indicated that in flat gold, a hydrophobic substrate, the solvent can restrict the protein movement, preventing residues from adsorbing [32]. This occurred because the wetting of the gold surface directly influences the protein behavior, building a barrier that inhibits adsorption. BMP-2 adsorption on gold occurs only through Van der Waals interactions due to the lack of partial charges. The VdW energy is weaker (less than $50 \mathrm{~kJ} / \mathrm{mol}$ ) than the electrostatic energy (more than $100 \mathrm{~kJ} / \mathrm{mol}$ ). Figure 2 shows the variation in interaction energies for different nanoscale topographies with BMP-2 molecules.

For shallow linear grating (SLG) and pillar (PLR) substrates, adsorption occurred within less than $2 \mathrm{~ns}$, while for deep linear grating (DLG), it occurred after $3 \mathrm{~ns}$. Simulation on flat surface occurred only after $13 \mathrm{~ns}$, reaching similar adsorption energy than simulation on pillars until $17 \mathrm{~ns}$; after that, it reached stronger adsorption, slightly less than both lineargrating structures.

The RMSD plot (Figure 4) of the atomic coordinates shows the structural stability of the systems. Surfaces FLT, SLG, and PLR had similar profiles and reached equilibration after $2 \mathrm{~ns}$. The DLG pattern induced an increase in RMSD, compared with the others, reaching equilibration after $8 \mathrm{~ns}$. In the DLG pattern, BMP-2 took longer to reach the bottom of the slot and, thus, had a delayed equilibration time of $8 \mathrm{~ns}$.

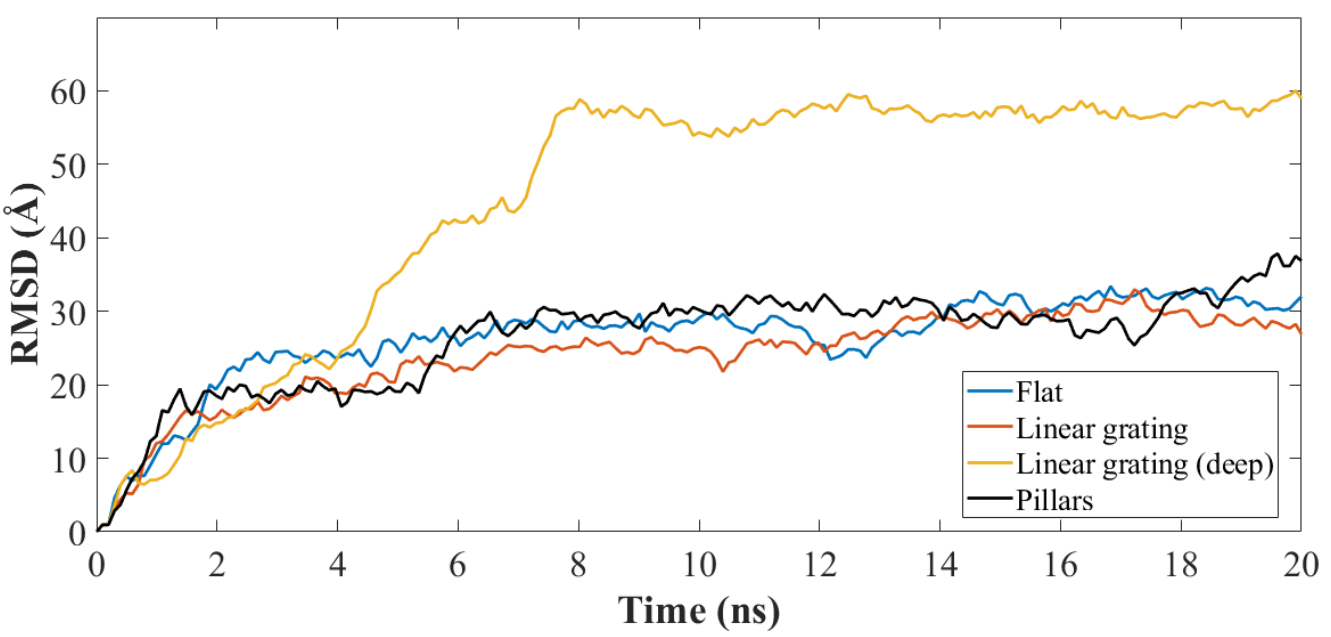

Figure 4. Root-mean-square deviation (RMSD) for different nanoscale topographies.

All simulations presented a similar radius of gyration $(\mathrm{Rg})$ profile, preserving most of the secondary structure as shown in Figure 5. The flat substrate had lower values of $\mathrm{Rg}$, less folding/unfolding, which correspond to lower adsorption energy. The Rg fluctuated 
between $18.5 \AA$ to $19.5 \AA$ for the duration of the simulation, as the end-on orientation has less flexibility to spread [22].

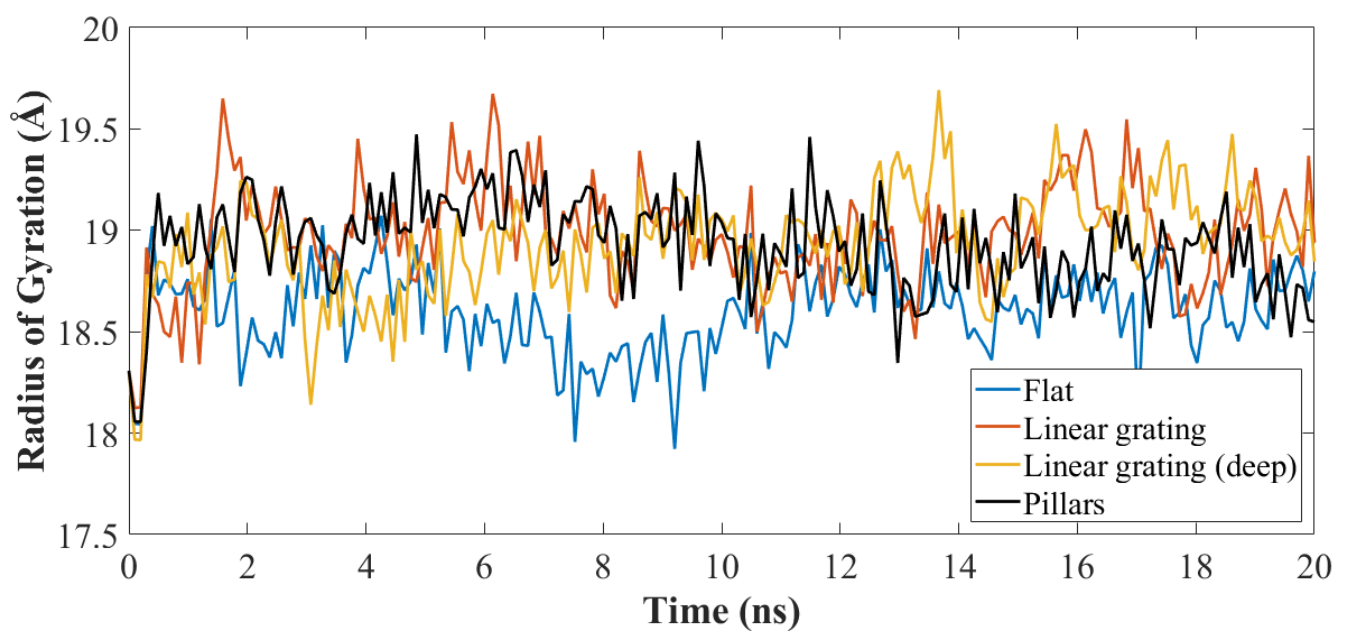

Figure 5. Radius of gyration for different nanoscale topographies.

Protein denaturation was evaluated by the analysis of the initial and final secondary structure of the protein (Table 1). Higher conformational changes occurred in the patterned surfaces, compared with flat patterns. No significant disruption of the secondary structure occurred for all configurations, which relates to the ability of the hydrophobic solvent to limit the protein movement on gold surfaces [31]. DLG lost part of its $\alpha$-helix and $\beta$-sheet structures, thus transforming into a coil structure.

Table 1. Initial and final BMP-2 secondary structure.

\begin{tabular}{|c|c|c|c|c|c|}
\hline $\begin{array}{l}\text { Secondary } \\
\text { Structure }\end{array}$ & $\begin{array}{c}\text { Initial } \\
\text { Structure }\end{array}$ & Flat & Pillar & $\begin{array}{l}\text { er } 20 \text { ns } \\
\text { Linear } \\
\text { Grating }\end{array}$ & $\begin{array}{c}\text { Linear Grating } \\
\text { Deep }\end{array}$ \\
\hline$\alpha$-helix & $10.38 \%$ & $10.38 \%$ & $15.09 \%$ & $11.32 \%$ & $9.43 \%$ \\
\hline $3_{10}$-helix & $0.00 \%$ & $0.00 \%$ & $2.83 \%$ & $2.83 \%$ & $0.00 \%$ \\
\hline$\beta$-sheet & $44.34 \%$ & $44.34 \%$ & $38.68 \%$ & $38.68 \%$ & $40.57 \%$ \\
\hline
\end{tabular}

The BMP-2 molecule residues have $\mathrm{N}-\mathrm{C}_{\alpha}$ and $\mathrm{C}_{\alpha}-\mathrm{C}$ bonds (carbonyl oxygen and amide hydrogen in transposition), which can freely rotate. The 3D orientation of the polypeptide backbone is determined by torsion or dihedral angle. Herein, the angle of rotation around $\mathrm{N}-\mathrm{C}_{\alpha}$ bond is denoted by phi $(\varphi)$ and around the $\mathrm{C}_{\alpha}-\mathrm{C}$ bond psi $(\psi)$, respectively. Figure 6 shows the distribution of phi $(\varphi)$ and psi $(\psi)$ torsion angles for different residues at the beginning and end of the simulation for different topographical configurations with the gold substrate. Wrist and knuckle epitopes with their respective residues are also shown, which participate in both SMAD pathways and adsorption with the gold substrate. The blue color represents the most favorable regions for the $\alpha$-helix and $\beta$-sheet, followed by green which is less favorable, and the white color shows the disallowed regions. A loss of secondary structure and subsequent bioactivity can occur when residues fall in the white regions of the Ramachandran plot. The BMP-2 structure shows that most of the amino acids are within the permitted backbone configurations for $\varphi / \psi$ angle pairs, for both DLG and PLR substrate topographies. 

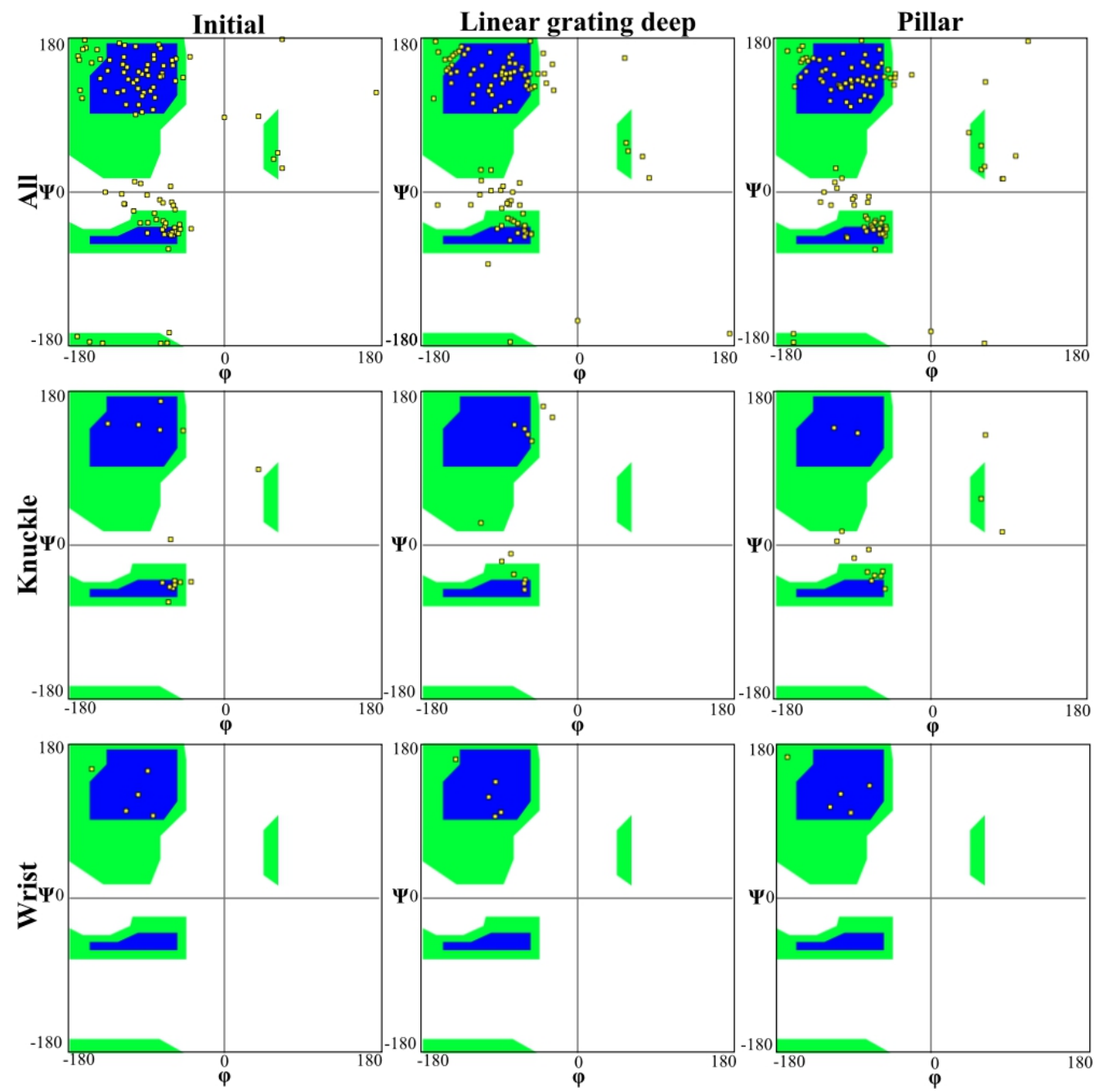

Figure 6. Ramachandran plots comparing different nanoscale topographies.

The Ramachandran plots for the wrist epitopes for both topographies show that residues are available to permit binding to type I and type II receptors, thereby initiating the SMAD signaling pathway, which, in turn, regulates downstream biological processes. The DLG displayed no steric hindrances for both the wrist and knuckle epitopes, indicating a stable and well-conformed secondary structure, as validated by $\alpha$-helix and $\beta$-sheet values shown in Table 1. In addition, a significant number of residues belonging to the wrist epitopes (Thr58, Leu55, Ala52, Phe49, Asn56) and knuckle epitopes in the DLG topography maintained their secondary structures, providing binding sites for type I and II receptors. In contrast, the wrist epitope for the PLR topography resulted in a minor loss of backbone structure for the antiparallel $\beta$-sheet residues (Ala52, Leu55, Asn56) and $\alpha$-helix residues (His54, Asp53), respectively. Thus, the Ramachandran plot clearly indicates favorable residues for both wrist and knuckle epitopes in the DLG topography that can promote successful adsorption and bioactivity.

The adsorbing residues were measured using the number of contacts within $5 \AA$ of the surface of the substrate (Figure 7). For FLT, SLG, and DLG substrates, the protein adsorbed with the $\alpha$-helix parallel to the surface. The pillar substrate had the $\alpha$-helix attached to the sidewalls of the gold substrate. Thus, the residues adsorption depended on the pattern type being used. The gold substrate, which is a hydrophobic material, restricted the movement of the BMP-2, limiting the residues from contacting the gold surface. 


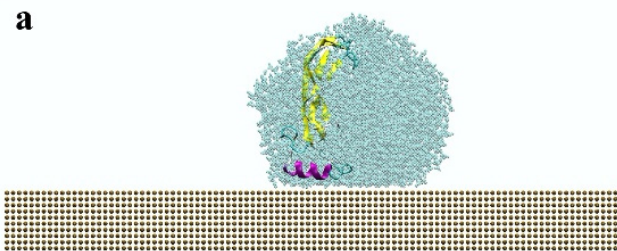

c

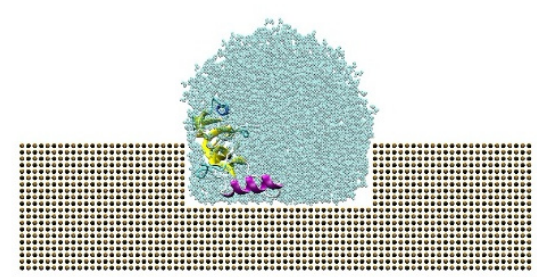

b

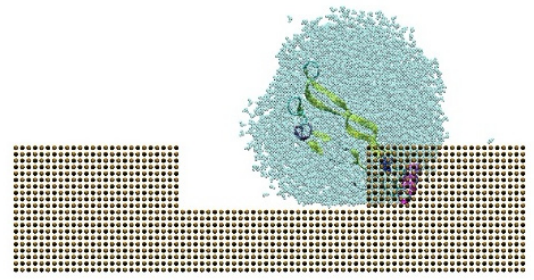

d

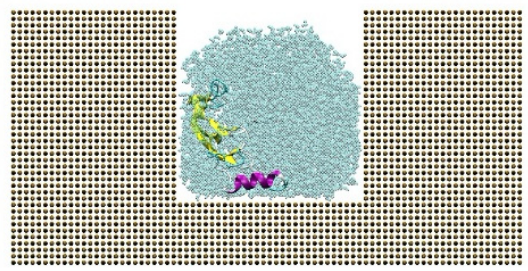

$\underline{20 \AA}$

Figure 7. Side view of the protein trajectory at 20 ns: (a) flat (FLT); (b) pillars (PLR); (c) shallow linear grating (SLG); (d) deep linear grating (DLG).

For the simulations performed on the flat substrate, at most, 26 atoms in a residue contacted the substrate. Within these residues, most were hydrophobic Val and Leu. For PLR substrate, hydrophobic residues Phe49 and Pro50, which belong to the wrist epitopes, were the primary residues to adsorb with up to 39 atoms; other residues adsorbed included polar Ser and hydrophobic Val and Leu. For both flat and PLR substrates, the presence of salt ions limited the adsorption, constraining the protein to the center of the drop.

On the SLG substrate, the protein assumed a more folded position with more residues exposed to the surface of the drop adsorbing. Predominant hydrophobic residues adsorbed, include Ala, Pro, Leu, Val, and Ile, with at most 40 atoms in each residue adsorbing. Residues had a stronger interaction during the simulations performed on DLG, with at most 88 atoms contacting the surface. Similar to SLG, the folded configuration allowed more residues near the water's surface, increasing the adsorption of hydrophobic residues Ala, Pro, Leu, Val, and Ile, and confirming that hydrophobic amino acid residues are more likely to adsorb on hydrophobic materials [41].

\section{Conclusions}

This research investigated the adsorption behavior of BMP-2 with end-on configuration on different nanopatterned gold materials using molecular dynamics simulations. The results indicate an increased absorption with deeper patterns. Ramachandran plots revealed no steric hindrances, for both wrist and knuckle epitopes. The secondary structures for $\alpha$-helix and $\beta$-sheet were preserved ensuring bioavailability for the SMAD signaling pathway. SLG and DLG substrates allowed more residues to be exposed to the water drop surface, thus increasing adsorption. Most residues belonging to the wrist and knuckle epitopes in the DLG topology preserved their secondary structures, thereby providing binding sites for type I and II receptors. The pillar pattern type had the $\alpha$-helix attached along the sidewalls of the substrate, whereas other pattern topologies had the protein adsorbed with the $\alpha$-helix parallel to the surface. This research forms the basis for understanding protein adsorption on patterned nanoscale gold and can be extended to other substrate types.

Author Contributions: Conceptualization, methodology, I.M. and S.D.; simulations, visualization, formal analysis, writing — original draft preparation, I.M.; molecular analysis, writing-review and editing, supervision, fund acquisition, S.D. All authors have read and agreed to the published version of the manuscript.

Funding: The authors would like to express their gratitude for funding support from the National Science Foundation Grant (NSF CMMI Award \#1663128, \#2100739, \#2100850) and the Center of Excellence in Product Design and Advanced Manufacturing at North Carolina A\&T State University. 
Institutional Review Board Statement: Not applicable.

Informed Consent Statement: Not applicable.

Data Availability Statement: The data presented in this study are available on request from the corresponding author.

Conflicts of Interest: The authors declare no conflict of interest. The funders had no role in the design of the study; in the collection, analyses, or interpretation of data; in the writing of the manuscript, or in the decision to publish the results.

\section{References}

1. Quan, X.; Liu, J.; Zhou, J. Multiscale modeling and simulations of protein adsorption: Progresses and perspectives. Curr. Opin. Colloid Interface Sci. 2019, 41, 74-85. [CrossRef]

2. Kim, J. Systematic approach to characterize the dynamics of protein adsorption on the surface of biomaterials using proteomics. Colloids Surf. B Biointerfaces 2020, 188, 110756. [CrossRef]

3. Gu, H.; Xue, Z.; Wang, M.; Yang, M.; Wang, K.; Xu, D. Effect of Hydroxyapatite Surface on BMP-2 Biological Properties by Docking and Molecular Simulation Approaches. J. Phys. Chem. B 2019, 123, 3372-3382. [CrossRef] [PubMed]

4. Marquetti, I.; Desai, S. Adsorption Behavior of Bone Morphogenic Protein (BMP-2) on Nanoscale Topographies. In Proceedings of the ASME NanoEngineering for Medicine and Biology Conference, Los Angeles, CA, USA, 21-24 August 2018.

5. Bose, S.; Robertson, S.F.; Bandyopadhyay, A. Surface modification of biomaterials and biomedical devices using additive manufacturing. Acta Biomater. 2018, 66, 6-22. [CrossRef] [PubMed]

6. Joshy, K.S.; Snigdha, S.; Thomas, S. Plasma Modified Polymeric Materials for Scaffolding of Bone Tissue Engineering. In Non-Thermal Plasma Technology for Polymeric Materials; Elsevier: Amsterdam, The Netherlands, 2019; pp. 439-458. [CrossRef]

7. Oliveira, A.F.; Gemming, S.; Seifert, G. Conformational Analysis of Aqueous BMP-2 Using Atomistic Molecular Dynamics Simulations. J. Phys. Chem. B 2010, 115, 1122-1130. [CrossRef] [PubMed]

8. Desai, S.; Bidanda, B.; Bártolo, P.J. Emerging Trends in the Applications of Metallic and Ceramic Biomaterials BT. In Bio-Materials and Prototyping Applications in Medicine; Bártolo, P.J., Bidanda, B., Eds.; Springer International Publishing: Cham, Switzerland, 2021; pp. 1-17. ISBN 978-3-030-35876-1.

9. Desai, S.; Shankar, M.R. Emerging Trends in Polymers, Composites, and Nano Biomaterial Applications. In Bio-Materials and Prototyping Applications in Medicine; Springer International Publishing: Cham, Switzerland, 2021; pp. 19-34.

10. US Food and Drug Administration. Premarket Approval (PMA). Infuse Bone Graft, Lt-Cage Lumbar Tapered Fusion Device. Available online: https://www.accessdata.fda.gov/scripts/cdrh/cfdocs/cfpma/pma.cfm?id=P000058 (accessed on 19 January 2022).

11. US Food and Drug Administration. Premarket Approval (PMA-P000054). Infuse Bone Graft, Filler Recombinant Human Bone Morphogenetic Protein, Collagen Scaffold, Osteoinduction. Available online: https:/ /www.accessdata.fda.gov/scripts/cdrh/ cfdocs / cfpma/pma.cfm?id=P000054 (accessed on 19 January 2022).

12. US Food and Drug Administration. Premarket Approval (PMA-P000053). Infuse Bone Graft, Bone Grafting Material, Dental, With Biologic Component. Available online: https:/ / www.accessdata.fda.gov/scripts/cdrh/cfdocs/cfpma/pma.cfm?id=P050053 (accessed on 19 January 2022).

13. James, A.W.; LaChaud, G.; Shen, J.; Asatrian, G.; Nguyen, V.; Zhang, X.; Ting, K.; Soo, C. A Review of the Clinical Side Effects of Bone Morphogenetic Protein-2. Tissue Eng. Part B Rev. 2016, 22, 284-297. [CrossRef]

14. Schwab, E.H.; Pohl, T.L.M.; Haraszti, T.; Schwaerzer, G.K.; Hiepen, C.; Spatz, J.P.; Knaus, P.; Cavalcanti-Adam, E.A. Nanoscale control of surface immobilized BMP-2: Toward a quantitative assessment of BMP-mediated signaling events. Nano Lett. 2015, 15, 1526-1534. [CrossRef]

15. Desai, S.; Harrison, B. Direct-Writing of Biomedia for Drug Delivery and Tissue Regeneration. In Printed Biomaterials; Springer: New York, NY, USA, 2010; pp. 71-89. ISBN 978-1-4419-1394-4.

16. Desai, S.; Perkins, J.; Harrison, B.S.; Sankar, J. Understanding release kinetics of biopolymer drug delivery microcapsules for biomedical applications. Mater. Sci. Eng. B Solid-State Mater. Adv. Technol. 2010, 168, 127-131. [CrossRef]

17. Desai, S.; Moore, A.; Harrison, B.; Sankar, J. Understanding microdroplet formations for biomedical applications. In Proceedings of the ASME International Mechanical Engineering Congress and Exposition, Lake Buena Vista, FL, USA, 13-19 November 2009; American Society of Mechanical Engineers Digital Collection: New York, NY, USA, 2009; Volume 15, pp. 119-123.

18. Tenkumo, T.; Vanegas Sáenz, J.R.; Nakamura, K.; Shimizu, Y.; Sokolova, V.; Epple, M.; Kamano, Y.; Egusa, H.; Sugaya, T.; Sasaki, K. Prolonged release of bone morphogenetic protein-2 in vivo by gene transfection with DNA-functionalized calcium phosphate nanoparticle-loaded collagen scaffolds. Mater. Sci. Eng. C 2018, 92, 172-183. [CrossRef]

19. Ekblad, T.; Liedberg, B. Protein adsorption and surface patterning. Curr. Opin. Colloid Interface Sci. 2010, 15, 499-509. [CrossRef]

20. Zhang, A.; Xie, Y.; Zhou, J. Experimental Control and Characterization of Protein Orientation on Surfaces. Prog. Chem. Beijing 2009, 21, 1408-1417.

21. Valera, E.; Isaacs, M.J.; Kawakami, Y.; Belmonte, J.C.I.; Choe, S. BMP-2/ 6 Heterodimer Is More Effective than BMP-2 or BMP-6 Homodimers as Inductor of Differentiation of Human Embryonic Stem Cells. PLoS ONE 2010, 5, e11167. [CrossRef] [PubMed] 
22. Kaito, T.; Morimoto, T.; Mori, Y.; Kanayama, S.; Makino, T.; Takenaka, S.; Sakai, Y.; Otsuru, S.; Yoshioka, Y.; Yoshikawa, H. BMP-2/7 heterodimer strongly induces bone regeneration in the absence of increased soft tissue inflammation. Spine J. 2018, 18, 139-146. [CrossRef] [PubMed]

23. Israel, D.I.; Nove, J.; Kerns, K.M.; Kaufman, R.J.; Rosen, V.; Cox, K.A.; Wozney, J.M. Heterodimeric Bone Morphogenetic Proteins Show Enhanced Activity In Vitro and In Vivo. Growth Factors 1996, 13, 291-300. [CrossRef]

24. Morimoto, T.; Kaito, T.; Matsuo, Y.; Sugiura, T.; Kashii, M.; Makino, T.; Iwasaki, M.; Yoshikawa, H. The bone morphogenetic protein-2/7 heterodimer is a stronger inducer of bone regeneration than the individual homodimers in a rat spinal fusion model. Spine J. 2015, 15, 1379-1390. [CrossRef]

25. Mücksch, C.; Urbassek, H.M. Adsorption of BMP-2 on a hydrophobic graphite surface: A molecular dynamics study. Chem. Phys. Lett. 2011, 510, 252-256. [CrossRef]

26. Dong, X.; Wang, Q.; Wu, T.; Pan, H. Understanding Adsorption-Desorption Dynamics of BMP-2 on Hydroxyapatite (001) Surface. Biophys. J. 2007, 93, 750-759. [CrossRef]

27. Mücksch, C.; Urbassek, H.M. Enhancing Protein Adsorption Simulations by Using Accelerated Molecular Dynamics. PLoS ONE 2013, 8, e64883. [CrossRef]

28. Oliveira, A.F.; Gemming, S.; Seifert, G. Molecular dynamics simulations of BMP-2 adsorption on a hydrophobic surface. Mater Werkst. 2010, 41, 1048-1053. [CrossRef]

29. Kausar, T.; Nayeem, S.M. Computational analysis on conformational dynamics of bone morphogenetic protein-2 (BMP-2). J. Biomol. Struct. Dyn. 2017, 35, 2224-2234. [CrossRef]

30. Marquetti, I.; Desai, S. Orientation effects on the nanoscale adsorption behavior of bone morphogenetic protein-2 on hydrophilic silicon dioxide. RSC Adv. 2019, 9, 906-916. [CrossRef]

31. Marquetti, I.; Desai, S. Molecular modeling the adsorption behavior of bone morphogenetic protein-2 on hydrophobic and hydrophilic substrates. Chem. Phys. Lett. 2018, 706, 285-294. [CrossRef]

32. Marquetti, I.; Desai, S. Adsorption Behavior of Bone Morphogenetic Protein-2 on a Graphite Substrate for Biomedical Applications. Am. J. Eng. Appl. Sci. 2018, 11, 1037-1044. [CrossRef]

33. Huang, B.; Lou, Y.; Li, T.; Lin, Z.; Sun, S.; Yuan, Y.; Liu, C.; Gu, Y. Molecular dynamics simulations of adsorption and desorption of bone morphogenetic protein-2 on textured hydroxyapatite surfaces. Acta Biomater. 2018, 80, 121-130. [CrossRef]

34. Tavanti, F.; Pedone, A.; Menziani, M.C. Multiscale Molecular Dynamics Simulation of Multiple Protein Adsorption on Gold Nanoparticles. Int. J. Mol. Sci. 2019, 20, 3539. [CrossRef]

35. Berman, H.M.; Westbrook, J.; Feng, Z.; Gilliland, G.; Bhat, T.N.; Weissig, H.; Shindyalov, I.N.; Bourne, P.E. The Protein Data Bank. Nucleic Acids Res. 2000, 28, 235-242. [CrossRef]

36. Towns, J.; Cockerill, T.; Dahan, M.; Foster, I.; Gaither, K.; Grimshaw, A.; Hazlewood, V.; Lathrop, S.; Lifka, D.; Peterson, G.D.; et al. XSEDE: Accelerating Scientific Discovery. Comput. Sci. Eng. 2014, 16, 62-74. [CrossRef]

37. MacKerell, A.D.; Bashford, D.; Bellott, M.; Dunbrack, R.L.; Evanseck, J.D.; Field, M.J.; Fischer, S.; Gao, J.; Guo, H.; Ha, S.; et al. All-atom empirical potential for molecular modeling and dynamics studies of proteins. J. Phys. Chem. B 1998, 102, 3586-3616. [CrossRef]

38. Braun, R.; Sarikaya, M.; Schulten, K. Genetically engineered gold-binding polypeptides: Structure prediction and molecular dynamics. Polym. Ed. 2002, 13, 747-757. [CrossRef]

39. Utesch, T.; Daminelli, G.; Mroginski, M.A. Molecular dynamics simulations of the adsorption of bone morphogenetic protein-2 on surfaces with medical relevance. Langmuir 2011, 27, 13144-13153. [CrossRef]

40. Phillips, J.C.; Braun, R.; Wang, W.; Gumbart, J.; Tajkhorshid, E.; Villa, E.; Chipot, C.; Skeel, R.D.; Kalé, L.; Schulten, K. Scalable molecular dynamics with NAMD. J. Comput. Chem. 2005, 26, 1781-1802. [CrossRef] [PubMed]

41. Schmidt, D.R.; Waldeck, H.; Kao, W.J. Protein Adsorption to Biomaterials. In Biological Interactions on Materials Surfaces; Springer: New York, NY, USA, 2009; pp. 1-18. [CrossRef] 